\title{
COPIM
}

\section{COPIM Community Governance Workshop Recap: Part 2 - On the Meaning of Community}

Sam Moore, Janneke Adema

Published on: Jun 15, 2020

DOI: $10.21428 / 785 a 6451 . d f e 7 d c 68$

License: Creative Commons Attribution 4.0 International License (CC-BY 4.0). 
"Community can be the warmly persuasive word to describe an existing set of relationships, or the warmly pervasive word to describe an alternative set of relationships. What is most important, perhaps, is that unlike all other terms of social organization (state, nation, society, etc.) it seems never to be used unfavorably, and never to be given any positive opposing or distinguishing term" (Raymond Williams, Keywords,_p.

'Community' is a slippery concept. To call something 'community-led' is to imply a set of values or practices that operate in distinction to top-down or market-led approaches. In the scholarly communication space, many projects rely on the term community-led (including our own COPIM project) to distinguish themselves from more privatised or profiteering forms of publishing. Community may connote inclusivity, informality and values-driven approaches to organisation; yet it is also illdefined and often used primarily because it has these positive associations. But what does it mean to describe something as community-led and how should the COPIM project understand its own community? This was the focus of the second half of our recent workshop on community governance (see the first post for more on the workshop and a list of participants).

\section{Defining communities?}

Citing the Raymond Williams quote above, Chris Land highlighted that community is rarely used 'unfavourably', which is to say that doing things in the name of community is framed primarily as a good thing. Community imparts a shared identity on a group of people, albeit an often ill-defined or unacknowledged one. This indefinability was also suggested by Cameron Neylon, whose co-authored Principles for Open Scholarly_ Infrastructure 'dodged' the task of defining a community because of how difficult it is to do in the abstract. Yet, for Neylon, working out who your 'community' actually is may be the most important question that a publishing infrastructure project needs to answer. For Katherine Skinner, this too is a key question: at what point should a project start referring to its 'community' (as opposed to its individual participants)?

Kathleen Fitzpatrick and Catherine Mitchell each suggested a more pluralistic understanding of communities over one individual community, or what Leslie Chan termed a 'community of communities', in order to recognise the various ways in which different groups overlap with a project and their differing needs. Reggie Raju built on 
this with the idea that community members may be defined as beneficiaries, partners and stakeholders with each group requiring different treatment and accountability measures. This emphasis on stakeholders, though often criticised for its corporatisation, was actually highlighted by Chris Land as holding radical potential in how it exposes certain 'material and economic interconnections between people' in a way that 'communities' might not do. This is especially important for making visible the inequalities inherent within communities, particularly around who does the actual work. Dave Ghamandi suggested that labour input is one of the crucial elements around defining community: who puts labour in, who benefits from this labour, and so on. This necessitates an expansive and intentional understanding of our stakeholders to include, for example, students, warehouse workers, and others in a variety of geographical and economic settings. How can COPIM identify and ensure accountability to these wider stakeholder networks, many of whom are without a voice in debates around scholarly publishing?

\section{Homogenisation and exclusion}

Part of the problem with talking about community, or even communities, is the risk of violence that leads from such homogenisation. The act of identifying a community will often obscure the difference within that community by implying that all members share a common identity (which may not be the case). Although these forms of violence are perhaps unavoidable, they also impact on our understanding of community in a myriad of ways. For example, community may imply locality when it in fact refers to a geographically and ideologically disparate number of participants, a point made by Arianna Becerril García about the AmeliCA initiative. In fact, homogenisation is often a clear feature of how advocates for open access in Europe and North America talk about Latin America, when in fact there are huge levels of diversity between various countries and local contexts. Community definitions therefore require attendance to detail and difference so as to not homogenise such diverse contexts.

Related to this is how communities also by definition lead to exclusion: someone has to be on the outside of the community for the term to make sense. Florence Piron described how community for her requires the adoption of a welcoming stance to all who wanted to participate, although she was also keen to emphasise that she does not feel part of the open access 'community' itself, primarily because of its anglophone nature that excludes many non-native English speakers. This is the paradox of community that can be simultaneously welcoming but also exclusionary. Again, community may appear homogenous from the outside, when it is in fact quite 
exclusionary within it. A handful of people may be making all the decisions that from the outside appear democratic. This also leads to questions of representative and direct governance structures, as Dave Ghamandi reminded us, and the pragmatic questions around who gets to speak on behalf of everyone else.

\section{Lessons for the COPIM project}

So, our understanding of community within the COPIM project must appreciate antagonism both within and outside what we are defining as our community. Being 'community-led' is not as simple as identifying a homogeneous group of people to whom we are answerable and/or steered by. It both leads to exclusion of certain perspectives and inclusion of a potential multitude of perspectives. This is especially the case for COPIM, which is composed of a number of different overlapping stakeholder groups, including publishers, researchers, librarians, and many others. We intend to be welcoming while also maintaining a coherent identity that pushes for grassroots and horizontal forms of open access monograph publishing.

As with our discussion on governance, much of the work here may come back to defining principles or norms that potential community members can agree upon as the basis for participation. Lidia Uziel explained how the COPIM project exists within a changing landscape and that having a strong set of values and principles will help distinguish our community from others in this space. Many people are supportive of the general trend towards openness in monograph publishing and so our values need to be articulated in a way that brings pre-existing communities on board as stakeholders. Yet there is, as Chris Land reminded us, a tendency to overthink such issues in a way that leads to over-bureaucratisation of a project. It is therefore important to consider that there is an uneven distribution of participation and labour input within the project, which means that horizontal and equitable governance could stifle the project if we try to account for every possible situation and how it may affect all members of the community.

\section{Community-Building}

So how should COPIM go about identifying and helping to build the various stakeholder communities that our work may impact? For Katherine Skinner, communities need to be 'nurtured' in a way that is processual rather than teleological: community-building is work that is never complete. Although it is often pragmatic to do so, Janneke Adema highlighted that building communities based on our own networks has the potential to replicate the kinds of power structures that we want to 
undermine through our work. Community-building requires an eye towards both the community that is and the one that is 'coming about'. For Kathleen Fitzpatrick, this is a continuous process that requires us to look at how communities are built and supported in a multitude of ways through interconnections with many other communities. Rather than seeing COPIM's community as one thing to be nurtured, then, we must be open to the linkages and relationalities with other communities that themselves can be nurtured. Community thus becomes less of a standalone thing and instead takes on a more rhizomatic quality that reveals the interconnectedness of our efforts.

This is where we see the idea of 'scaling small' playing a key role in the future of COPIM's community-building efforts. As a guiding principle of the COPIM project, we are interested in expanding the reach of open monograph publishing through mutual reliance. This means figuring out ways to support one another through sharing resources and working on collective infrastructure projects (as COPIM is doing), crucially while maintaining the identity of the individual projects within the ecosystem. This is in opposition to economies of scale that have a natural tendency to homogenise and flatten difference through the need to funnel everything through their standardised process. As Chris Land explained, 'scaling small' allows for the collective coordination of resources across a 'diverse ecology of organisations' that creates a meta community, or a community of communities, for the provision of diverse approaches to publishing. We must keep this in mind when designing systems of governance for the COPIM project.

Header image: " Range stage " by Jay Mantri , $\underline{\mathrm{CCO}}$.

\section{Citations}

1. Williams, R. (1976). Keywords: A Vocabulary of Culture and Society. Oxford University Press. $€$ 